\title{
¿ESTÁ LA PRENSA EN LOS EE. UU. PERDIENDO LA PROTECCIÓN DE LA PRIMERA ENMIENDA?*
}

\author{
Ronald Dworkin
}

Éste es uno de los trabajos más interesantes de los varios que Ronald Dworkin ha dedicado a la libertad de expresión. A la luz del análisis crítico de un conjunto de casos constitucionales decididos en Estados Unidos durante la década de 1970 y principios de los años ochenta, Dworkin reflexiona sobre esta libertad fundamental para la comunidad política democrática. El filósofo del derecho vuelve aquí sobre uno de los postulados más importantes de su carrera: la necesidad de distinguir, a la hora de la reflexión constitucional, entre argumentos de principio y argumentos de política. Entre otras cosas, usa esta distinción para advertir contra los riesgos que, para la libertad de expresión, se derivan de ciertas pretensio-

Ronald Dworkin. Filósofo del derecho y destacado autor contemporáneo en el ámbito de la filosofía jurídica y política. BA. en filosofía y LL. B. Universidad de Harvard; M. A. en jurisprudencia, Magdalen College, Universidad de Oxford. Fue titular de la cátedra Wesley N. Hohfeld de Jurisprudencia en la Universidad de Yale, y actualmente es catedrático de la Universidad de Nueva York. Entre sus obras traducidas al castellano están La Democracia Posible (Ed. Paidós), La Justicia con Toga (Ed. Marcial Pons), Virtud Soberana (Ed. Paidós), El Dominio de la Vida (Ed. Ariel), El Imperio de la Justicia (Editorial Gedisa), Los Derechos en Serio (Ed. Ariel).

* Publicado originalmente en The New York Review of Books, Vol. 27, número 19, 4 de diciembre de 1980. Traducido y reproducido en esta edición con autorización del autor y de The New York Review of Books (C), 1980.

Traducción al castellano de Estudios Públicos. Se agradece la valiosa colaboración de Andrea Álvarez en la preparación del borrador inicial de la traducción.

Estudios Públicos, 114 (otoño 2009). 
nes de la profesión periodística. Por ejemplo, la pretensión de que la sociedad, entendida como un todo, tendría un derecho a recibir información, información cuya entrega constituye el oficio periodístico. Para Dworkin esta pretensión transforma al derecho a la libertad de expresión en una cuestión de política y no de principio. Al permitir esta transformación, el periodismo contribuye en la práctica a debilitar una libertad que dice valorar y querer reforzar.

Palabras clave: Primera Enmienda, libertad de expresión, teoría constitucional, revisión judicial, ejercicio del periodismo, censura.

E scritores y periodistas han tenido altibajos últimamente en las cortes estadounidenses. La prensa está preocupada por una serie de decisiones judiciales que estima disminuirán drásticamente las atribuciones de los periodistas y reducirán la función de la Primera Enmienda de la Constitución* en la sociedad estadounidense. Una de ellas fue la asombrosa decisión de la Corte Suprema en el caso United States v. Snepp, en 1980, que sentenció al autor de un libro a entregar al gobierno todas las ganancias obtenidas por su publicación, sin siquiera haber dado lugar a una audiencia sobre el asunto. Pero la prensa también ha ganado las que son, a su juicio, victorias importantes. Una de ellas fue el caso Richmond Newspapers, también de 1980, en el que la Corte revirtió el fallo que había emitido en un caso anterior y sostuvo que los periodistas, al menos en principio, tienen derecho a estar presentes en los juicios penales incluso cuando el acusado quiere que se los excluya ${ }^{1}$.

* La Primera Enmienda de la Constitución de los EE.UU. dice así: "El Congreso no promulgará ley alguna referente a la instauración de una religión, o que prohíba la libre profesión de una religión; o que limite la libertad de expresión, o de la prensa; o el derecho de la gente a reunirse en forma pacífica, o a solicitar del Gobierno la reparación de un agravio". ("Congress shall make no law respecting an establishment of religion, or prohibiting the free exercise thereof; or abridging the freedom of speech, or of the press; or the right of the people peaceably to assemble, and to petition the Government for a redress of grievances.”) (N. del E.)

${ }^{1}$ El caso anterior había sido el de Gannet v. DePasquale, fallado un año antes, que dejó a la prensa muy disgustada. El fallo sostuvo que un juez podía impedir la presencia de reporteros en las audiencias preliminares. En el caso Richmond Newspapers, el juez Burger, que presidía la Corte, manifestó que al fallo anterior (Gannet v. DePasquale) sólo era aplicable en las audiencias preliminares y no en los juicios. Pero la opinión del propio juez Burger en el caso Gannet, al igual que las opiniones de otros 
El caso United States v. Snepp es sin duda el más importante de ambos. Al ingresar a la CIA, Frank Snepp firmó un contrato en el que aceptó someter a revisión de la institución, antes de su publicación, todo lo que posteriormente pudiese escribir sobre ella. La CIA sostiene que este consentimiento, que obtiene de todos sus agentes, es necesario, pues así puede determinar de antemano si alguna parte del material que un autor pretende publicar es de carácter reservado, y adoptar acciones legales para imponer lo que a su entender es material "reservado" cuando el autor discrepe de su opinión. Después de retirarse de la CIA, Snepp escribió un libro titulado Decent Interval, en el que criticó fuertemente la conducta de la CIA durante los últimos meses de la guerra en Vietnam. Snepp temía que la agencia usara su derecho a revisar el manuscrito para dilatarlo y acosarlo afirmando que asuntos sin importancia para la seguridad nacional eran reservados, como ciertamente lo había hecho antes en el caso de Victor Marchetti, otro ex agente que había escrito y sometido un libro a la revisión de la CIA². Luego de mucha indecisión, Snepp decidió publicar el libro sin someterlo a la revisión previa de la CIA.

La CIA lo demandó por incumplimiento de contrato. Snepp alegó que la Primera Enmienda invalidaba su contrato por ser una forma de censura. Pero ni el Juzgado Federal ni la respectiva Corte de Apelaciones, a la cual apeló Snepp, aceptaron su alegato. El juez federal dictaminó que Snepp debía entregar al gobierno, a modo de reparación, todas las ganancias que había obtenido por su libro — sus únicos ingresos por su trabajo de varios años. Sin embargo, la Corte de Apelaciones revirtió la decisión del Juzgado Federal en este punto, declarando que el gobierno debía contentarse con la indemnización de perjuicios equivalente al daño efectivo causado por la publicación del libro, que es la reparación habitual en casos de incumplimiento de contrato.

Snepp apeló a la Corte Suprema invocando nuevamente la Primera Enmienda. El gobierno le solicitó a la Corte que no admitiera la revisión del caso, señalando que dadas las circunstancias se conforma-

jueces, parecía incluir también la posibilidad de exclusión de los periodistas en los juicios propiamente tales, por lo que en el fallo del caso Richmond Newspapers hubo probablemente un cambio de parecer, tal como lo dice el juez Blackmun en su opinión disidente en este caso.

${ }^{2}$ Marchetti, Victor y John D. Marks: The CIA and the Cult of Intelligence, 1974. 
ba con la indemnización asignada por la Corte de Apelaciones. Pero agregó que si la Corte Suprema decidía revisar el caso, aprovecharía la oportunidad para alegar a favor de que se revirtiera la resolución de la Corte de Apelaciones y se reinstaurase la pena más gravosa que había ordenado el Juzgado Federal. Contrariamente a los deseos del gobierno, la Corte acogió el recurso, pero, al final, sólo para reinstaurar la pena más onerosa. La Corte hizo esto, contraviniendo todas las tradiciones de imparcialidad judicial y sin darle a nadie la oportunidad de exponer sus argumentos. Una corte, en la que supuestamente prevalece el ideal de mesura (judicial restraint) de los jueces, torció los principios de la imparcialidad procesal para arribar a un resultado que ninguna de las partes había solicitado.

Algunos periodistas han especulado que la Corte estaba enfurecida con la prensa por el libro The Brethren, escrito por Woodward y Armstrong en 1980, que contaba la "historia secreta" de la Corte, y que ésta había aprovechado la oportunidad para vengarse. Pero muchos abogados defensores de la Primera Enmienda opinan que se trata de algo preocupante y que este caso es tan sólo el ejemplo más reciente y dramático del debilitamiento que está sufriendo la libertad de expresión en los Estados Unidos.

Vale la pena describir con algún detalle la evidencia a favor de esta opinión pesimista. Ningún prominente abogado constitucionalista (salvo el juez Black) ha pensado alguna vez que la Primera Enmienda le impida al gobierno regular de alguna manera la libertad de expresión. Siempre ha existido la posibilidad de que las personas demanden a otras en la Corte por injurias y difamación, por ejemplo, e incluso los más fervientes defensores de la libertad de expresión han admitido que nadie tiene un derecho constitucional a dar alarma de incendio gritando "fuego" en un teatro lleno de personas, o a publicar información sobre movimientos de tropas en tiempo de guerra. Sin embargo, cuando la libertad de expresión entra en conflicto con otros intereses, la preocupación de la Corte por la libertad de expresión ha tenido mareas altas y bajas, y algunos sostienen que actualmente nos encontramos en un momento en que la marea está sumamente baja.

La Corte presidida por el juez Warren llegó muy lejos, por ejemplo, en lo que se refiere a proteger de la censura a la pornografía, sobre la base de que no le compete al Estado determinar qué cosas debería o no debería la gente, en privado, considerar como de mal gusto o vergon- 
zosas. Pero la Corte del juez Burger aceptó la idea de censura conforme con las pautas locales de la decencia, moral y buenas costumbres, y si bien este criterio no ha planteado ningún problema a los productores de pornografía de Times Square, ha hecho que muchos cines de ciudades y pueblos pequeños se hayan vuelto muy cautelosos. Otro ejemplo son las demandas por injurias y difamación entabladas por figuras públicas contra los diarios. En el famoso caso Times v. Sullivan, la Corte del juez Warren sostuvo que una persona pública no podía demandar por injurias a un periódico aun cuando lo publicado fuese falso y perjudicial, salvo que ella lograra probar que lo publicado no sólo era meramente falso sino que además hubo ya sea intención maliciosa o ya sea imprudencia por parte del periódico. La Corte sostuvo que debía suponerse que las figuras públicas han renunciado a su derecho a demandar por simples tergiversaciones.

La Corte del juez Burger no ha invalidado la sentencia del caso Sullivan, pero acotó la clase de personas a tener en cuenta como figuras públicas para estos efectos, y en el caso Herbert $v$. Landau sostuvo que incluso cuando una figura pública interpone una demanda, los periodistas podrán ser interrogados, bajo juramento, respecto de sus métodos de investigación y criterios editoriales, con el fin de demostrar su malicia o imprudencia. La Corte rechazó la queja de los diarios y canales de televisión de que la amenaza de tales interrogaciones, en las cuales los periodistas se verían forzados a defender criterios en gran parte subjetivos, inhibiría seriamente la libertad de los periodistas para investigar, restándole por ende efectividad a su servicio público.

Dos de los recientes fallos más importantes relacionados con la Primera Enmienda jamás llegaron a la Corte Suprema. El primero fue el publicitado caso del periodista Myron Farber, del New York Times, el que discutí tiempo atrás en un artículo ${ }^{3}$. Las cortes de New Jersey sostuvieron que Farber podía ser detenido y encarcelado por desacato si se negaba a entregar sus archivos, los que tal vez podían contener información útil para los abogados de la defensa de un individuo acusado de asesinato. The New York Times (con el respaldo de otros diarios) argumentó que si los periodistas no son capaces de garantizar reserva a sus informantes, sus fuentes desaparecían y el público perdería una

\footnotetext{
${ }^{3}$ Dworkin, Ronald: “The Rights of Myron Farber”, 1978.
} 
importante fuente de información. Pero las cortes no aceptaron el argumento 4 .

El segundo caso, The Progressive, aun cuando terminó en comedia, fue sin embargo la ocasión para que fuese concedida por vez primera vez en los Estados Unidos una orden judicial precautoria de censura previa de una publicación. La revista en cuestión se proponía publicar un artículo titulado "El Secreto de la Bomba-H: Cómo lo Conseguimos, Por Qué lo Contamos”, y lo sometió a la Comisión de Energía Atómica (Atomic Energy Commission) para una aprobación informal. El autor, de hecho, sólo había usado en el artículo información pública y legalmente asequible. No obstante, la Comisión se negó a darle el pase al reportaje y entabló una demanda judicial para prohibir su publicación, declarando que, conforme a la Ley de Energía Atómica (Atomic Energy Act), toda información relativa a las armas nucleares es "inherentemente reservada” y no puede publicarse sin la autorización previa de la Comisión. La Comisión persuadió al juez de una corte distrital, quien escuchó en secreto el testimonio del gobierno, de que la publicación sería perjudicial para la seguridad nacional porque podría permitirle a un país pequeño - Uganda, encabezado por Idi Amin, era el ejemplo del momento- construir una bomba de hidrógeno.

La revista The Progressive apeló contra la prohibición ante la Corte de Apelaciones. Sin embargo, antes de que la Corte actuara, se hizo evidente que la información usada por el autor estaba al alcance de cualquiera en una biblioteca pública que era financiada por la Comisión, y varios periódicos y revistas publicaron entonces los contenidos del artículo propuesto sin solicitar autorización. El gobierno echó pie atrás con cierto bochorno y el reportaje de The Progressive fue finalmente publicado. Sin embargo, era un mal presagio el hecho de que la Primera Enmienda hubiese proporcionado tan poca protección en este caso. El argumento de "reserva inherente" que usó la Comisión —esto es, que es ilegal publicar cualquier información relativa a las armas atómicas sin que haya sido específicamente autorizada - es absurdamente amplio y, a mi juicio, no habría sido acogido en tribunales de jerarquía superior. Pero las cortes quizás habrían admitido un procedimiento que permitiera que un juez decida casos particulares de censura en sesiones

\footnotetext{
${ }^{4}$ Tampoco lo aceptó la Cámara de los Lores en Gran Bretaña cuando la British Steel Corporation demandó judicialmente a la estación Granada de TV con el fin de obtener el nombre de un informante en la administración de la Steel Corporation.
} 
secretas donde los "expertos" técnicos del gobierno podrían alarmar al juez, ejerciendo así una influencia indebida. La era atómica no es un ambiente sano para la libertad de expresión.

No toda la evidencia acerca del actual debilitamiento de la libertad de expresión proviene de fallos judiciales. La Ley de Libertad de Información (Freedom of Information Act), que fue reforzada por el Congreso tras el escándalo de Watergate, estipula que cualquier persona puede acceder a cualquier información en manos del gobierno federal, con algunas excepciones para proteger la privacidad de las personas, los secretos comerciales, la seguridad nacional, u otros similares. Gracias a esta ley hemos podido acceder a mucha información valiosa, como por ejemplo a algunas partes del libro sobre Camboya escrito por William Shawcross. Pero la presión a favor de una enmienda sustancial sigue en aumento. Los médicos han señalado que algunos experimentos del tipo doble ciego destinados a probar nuevos medicamentos y procedimientos se malogran cuando los periodistas descubren información que destruye la reserva necesaria para que el experimento sea estadísticamente significativo. Los científicos sostienen que el incentivo para llevar a cabo investigaciones podría verse comprometido cuando los diarios difunden detalles interesantes de postulaciones a fondos. El Centro Nacional de Control de Enfermedades ha declarado que los hospitales no recurren a su ayuda para localizar infecciones intrahospitalarias cuando los periodistas pueden poner a disposición de potenciales demandantes los informes que el Centro emite a los hospitales.

La CIA ya se beneficia de un eximente específico en la Ley de Información, el cual le permite retener información por motivos de seguridad nacional. Ahora busca una reserva mucho mayor - y dado el clima de preocupación por mejorar los servicios de inteligencia a raíz de la ocupación de la embajada estadounidense en Irán, podría obtenerla. El Departamento de Justicia, por ejemplo, está patrocinando una enmienda (HR7056) que eximiría de la ley cualquier cosa que la CIA estime que sea información obtenida de fuentes no gubernamentales, o información que tienda a identificar fuentes de inteligencia, o información relacionada con los sistemas de recolección de información de inteligencia. La enmienda propuesta estipula expresamente que las decisiones de la CIA de retener información por la vía de determinar que pertenece a una de estas categorías no podrá ser revisada por corte 
alguna. Hasta ahora, sin embargo, el comité del Senado que se ocupa de los asuntos de la CIA se ha opuesto a esas restricciones.

El Congreso, sin embargo, está dando pasos para la aprobación de una nueva ley que establece que es un delito el que un ex agente de la CIA o cualquiera otra persona publique el nombre de un agente en servicio. La versión del Senado del proyecto de ley, tal como fue modificado por el Comité de Inteligencia, estipula ahora que aquellas otras personas que no sean ex agentes o agentes en servicio, no quedarán sujetas a esa prohibición de dar a conocer los nombres de agentes, salvo que lo hagan como parte de un "patrón o práctica". El informe del Comité indica que esta salvedad tiene por finalidad proteger a los "periodistas prestigiados" (mainline journalists). Pero la salvedad es tan vaga que, en realidad, ofrece escasa protección, y el proyecto, de ser constitucional, sin duda restringirá las investigaciones que puedan realizar los periodistas sobre la CIA.

La prensa, como señalé antes, no ha perdido todas sus batallas. En el caso Richmond Newspapers, la Corte del juez Burger rechazó unánimemente el intento de la administración de Nixon por evitar la publicación de los Documentos del Pentágono (Pentagon Papers), y declaró que los medios de comunicación tienen cierta posición protegida constitucionalmente por la Primera Enmienda, con fuerza suficiente como para que el juez que preside un proceso judicial deba dar una razón especial para prohibir el acceso de los periodistas en un juicio penal. Con todo, la prensa cree que en general está perdiendo terreno.

\section{II}

El vasto libro de Nat Hentoff sobre la historia de la Primera Enmienda ${ }^{5}$ describe el origen de la idea de libertad de expresión y de la libertad de prensa en los Estados Unidos desde Peter Zenger en adelante. El autor, con manifiesta tristeza, hace notar los síntomas de lo que él simplemente interpreta como su actual desmoronamiento. El libro es notablemente fácil de leer y variado. Tiene el mérito de mostrar cómo la idea de la libertad de expresión asume distintos contenidos a medida que los subyacentes temas sustantivos varían desde la política educa-

${ }^{5}$ Hentoff, Nat: The First Freedom: The Tumultuous History of Free Speech in America, 1979. 
cional hasta la obscenidad y los reportajes sobre juicios penales. El tono del libro parece ecuánime. Los argumentos de Hentoff se basan primordialmente en citas de otros. Sin embargo, no hay duda alguna respecto de su postura en este tema. Él es partidario de la libertad de expresión y en su libro hay victorias y derrotas en pos de la libertad, héroes y cobardes de la prensa, y amigos y enemigos de la libertad.

Pero el texto no hace gran esfuerzo por analizar los fundamentos filosóficos de la libertad de expresión o de la libertad de prensa, ni tampoco por ver los límites de las libertades y prerrogativas que Hentoff quiere defender. En este aspecto es el clásico periodista que se lamenta por el destino de la Primera Enmienda en las cortes, aunque escribe mejor y con más entusiasmo y conocimientos que la mayoría. La prensa considera esta Enmienda como una especie de fuero privado y combate en forma más o menos automática todo rechazo de las cortes a reconocer en ese fuero alguna protección adicional. Los periódicos y las redes de comunicación denunciaron con virulencia las resoluciones judiciales en los casos Farber y Herber, incluso con más virulencia aún que en los casos The Progressive y Snepp.

Sin embargo, esta estrategia de apelar automáticamente a la Primera Enmienda es, a mi entender, equivocada, incluso si la única intención de la prensa fuese expandir sus facultades legales tanto como sea posible. Porque si se populariza la idea de que la Primera Enmienda es un escudo multiuso para periodistas, que los protege de juicios por injurias y difamación, destituciones, investigaciones y censura, se convertirá por ende en un escudo débil, puesto que parecerá obvio que un poder tan enorme de la prensa debería equilibrarse con otros intereses privados y sociales existentes en la comunidad. Lo que entonces sufrirá será la función medular histórica de la Primera Enmienda, que es simplemente la de garantizar que todos aquellos que deseen expresarse sobre temas políticos y sociales controvertidos tienen la libertad de hacerlo. Tal vez la sorprendente debilidad de la Primera Enmienda para proteger a los procesados en los casos The Progressive y Snepp, por ejemplo, sea en parte consecuencia de la misma efectividad con que los medios persuadieron a las cortes, en alguna época pasada, de que el poder de la Primera Enmienda se extiende mucho más allá de los casos directamente relacionados con la censura.

Para determinar si hay evidencia para esta sospecha, debemos considerar un tema que Hentoff y otros amigos de la Primera Enmienda 
pasan por alto. ¿Cuál es el fin de la Primera Enmienda? ¿A quién debe proteger? Hay una variedad de opiniones posibles en este tema. La teoría que predomina entre los abogados constitucionalistas en los Estados Unidos considera que los derechos constitucionales de la libertad de expresión -incluida la libertad de prensa, que en lenguaje constitucional se refiere a la palabra publicada en general y no a los periodistas en particular - están destinados a proteger al público receptor. Es decir, no protegen a quien habla o al escritor mismo sino al público al que éste se quiere dirigir. Según este punto de vista los periodistas y otros escritores están protegidos de la censura para que el público en general pueda tener acceso a la información que necesitan para votar y dirigir sus asuntos con inteligencia.

En su famoso ensayo On Liberty, John Stuart Mill ofreció una justificación similar pero más fundamental del derecho a la libertad de expresión. Mill dice que si todos tienen libertad para proponer cualquier teoría sobre la moral pública o privada, sin importar cuan absurda o impopular pudiese ser ésta, mayor será la probabilidad de que la verdad brote del mercado de ideas resultante, y la comunidad como un todo estará en mejores condiciones que lo que estaría si se censuraran las ideas impopulares. De nuevo, según esta explicación, a los individuos particulares se les permite expresarse libremente para que pueda beneficiarse en el largo plazo la comunidad a la cual se dirigen.

Pero otras teorías de la libertad de expresión — que en sentido amplio incluyen a la prensa - sostienen que el derecho está destinado a proteger al orador, esto es, que los individuos tienen derecho a hablar, no para el beneficio de otros sino porque ellos mismos sufrirían un daño inaceptable si fuesen censurados. Quienquiera que adhiera a esta postura debe explicar, desde luego, por qué la censura constituye una lesión más gravosa que otras formas de regulación. Debe demostrar por qué una persona sufre un menoscabo mayor cuando se le prohíbe hablar libremente de política que cuando, por ejemplo, excede los límites de velocidad, viola la propiedad privada o se ha fusionado con otros para restringir el comercio.

Podrían proponerse distintas teorías: que la censura es degradante porque sugiere que el que habla o escribe no merece la misma consideración que los demás ciudadanos, o que sus ideas no merecen el mismo respeto; que la censura es insultante porque le niega la igualdad de expresión en política y por ende vulnera su condición de ciudadano libre e igual; o que la censura es grave porque inhibe el desarrollo 
de su propia personalidad e integridad. Mill formula algo parecido a esta última afirmación en On Liberty, aparte de exponer su argumento del mercado-de-ideas, por lo que se puede decir que su teoría se preocupa de proteger al emisor y también al receptor.

Las teorías que se preocupan de proteger a la audiencia formulan generalmente lo que he llamado un argumento de política en defensa de la libertad de expresión y de la libertad de prensa ${ }^{6}$. Es decir, en estas teorías se argumenta que los periodistas deben tener ciertas prerrogativas, no porque ellos u otros tengan derecho a una protección especial, sino con el fin de garantizar algún beneficio general para la comunidad como un todo, así como los agricultores deben recibir a veces ciertos subsidios del Estado, no para su beneficio personal sino para garantizar también un beneficio para la comunidad. Por otro lado, las teorías que se preocupan de proteger al emisor formulan argumentos de principio para defender la libertad de expresión. Sostienen que la posición especial del emisor, como alguien que quiere expresar sus convicciones en materias de importancia política o social, le da derecho, en justicia, a gozar de una consideración especial, incluso si la comunidad como un todo pudiese verse perjudicada por permitirle expresarse. De modo que el contraste es enorme: en el primer caso el bienestar de la comunidad sirve de fundamento para la protección de la libertad de expresión, mientras que, en el segundo, el bienestar de la comunidad es ignorado con el fin de entregar esa protección a la libertad de expresión.

La distinción es relevante para la presente discusión en muchas formas. Si la libertad de expresión se justifica por motivos de política, luego cabría otorgarles a los periodistas privilegios y poderes especiales a los que no pueden acceder los demás ciudadanos, puesto que ellos [los periodistas] realizan una función importante y, de hecho, indispensable al proveer de información al público en general. Pero si la libertad de expresión se justifica por un asunto de principios, entonces sería inaceptable suponer que los periodistas debieran gozar de una protección especial que otros no tienen, porque eso significaría afirmar que ellos, en cuanto individuos, son más importantes o dignos de mayor consideración que otros.

Puesto que las facultades que la prensa exige, tal como la posibilidad de estar presente en juicios penales, deben ser especiales y sólo

${ }^{6}$ Véase Dworkin, Ronald: Taking Rights Seriously, 1977. 
para ella, es natural que los medios de comunicación favorezcan una concepción de la libertad de expresión basada en el argumento de política que se preocupa de proteger a la audiencia: a saber, que la prensa es esencial para que el público se informe. Sin embargo, en esta versión hay un peligro correlativo. Si se justifica la libertad de expresión como un asunto de política, luego cada vez que se tome una decisión respecto a si la libertad de expresión requiere de un eximente o privilegio adicional, entonces otras dimensiones rivales del interés del público deberán sopesarse con el interés de ese mismo público por la información.

Supongamos, por ejemplo, que se discute si la Ley de Libertad de Expresión debería enmendarse para que el Centro de Control de Enfermedades no se vea obligado a proveer información a los periodistas; o si la Comisión de Energía Atómica debería tener la facultad de prohibir que una revista publique un artículo que podría facilitar el acceso de otras potencias mundiales a información atómica. El interés general del público a estar bien informado exige oponerse, en ambos casos, a la reserva y a la publicación. Pero también es de interés público que los hospitales sean higiénicos y que no haya peligro nuclear, por lo que es necesario sopesar estos dos tipos de intereses, como en los análisis de costo-beneficio, para determinar dónde yace el interés general del público. Supongamos que en el largo plazo (tomando también en cuenta los posibles efectos secundarios) el público perdiera más, en su conjunto, si dicha información fuese publicada. Sería contradictorio, entonces, argumentar que esa información se debería publicar en aras del interés del público, y el argumento a favor de la libertad de expresión, por motivos de política, sucumbiría.

El problema es muy diferente, en cambio, si tomamos la libertad de expresión como un asunto de principios. Pues ahora cualquier conflicto entre la libertad de expresión y el bienestar de la sociedad no es un seudoconflicto entre dos aspectos del interés del público que se pudiesen amalgamar en cierta opinión sobre el interés de la sociedad en su conjunto. Es un conflicto genuino entre los derechos de un emisor particular como individuo y los intereses rivales de la sociedad como un todo. Salvo que el interés rival sea de gran envergadura - por ejemplo, que la publicación pueda originar una situación de emergencia u otro grave peligro-, el derecho del individuo debe primar por sobre el interés social, puesto que eso es lo que significa suponer que él tiene este tipo de derecho. 
Por lo tanto, cuando la prensa reclama algún privilegio o protección especial, es importante decidir si ese reclamo se basa en un asunto de principios o de política. La importancia de esta distinción se ha visto algunas veces minimizada por una concepción que últimamente se ha puesto de moda, a saber, que el público tiene lo que se ha llamado un "derecho a conocer" la información que puedan conseguir los periodistas. Si eso simplemente quiere decir que el público tiene un interés en el conocimiento — que la comunidad estará mejor, manteniéndose todo lo demás igual, si sabe más que si sabe menos sobre, por ejemplo, juicios criminales o postulaciones a fondos o secretos atómicos-, entonces sólo estamos replanteando el conocido argumento de política a favor de una prensa libre y poderosa: un público más informado se traducirá en una mejor sociedad en general. Pero la proposición de que el público tiene un derecho a saber sugiere algo mucho más fuerte que eso, a saber, que hay un argumento de principio, protector-de-la-audiencia, a favor de cualquier privilegio que incremente la capacidad de la prensa para recoger noticias.

Pero esa sugerencia más fuerte es, de hecho, muy engañosa. Es incorrecto suponer que miembros individuales de la comunidad tienen, en cualquier sentido fuerte, el derecho de conocer los asuntos que los periodistas deseen investigar. A ningún ciudadano se le habría negado su igualdad, independencia o integridad si, por ejemplo, Farber no hubiese escrito alguno de sus reportajes en el New York Times sobre el Dr. Jascalevich, y ninguno de ellos podría haber interpuesto una demanda contra Farber obligándolo a escribirlos, o exigiendo una indemnización de daños por no haberlo hecho. Tal vez la situación del ciudadano promedio se hubiese visto desmejorada si estos reportajes no se hubiesen escrito, pero ése es un asunto del bienestar general de la sociedad, no de un derecho individual.

Cualquiera sea el caso, lo que se supone es que el presunto derecho a saber es un derecho del público en su conjunto y no de un ciudadano en particular. Lo que resulta prácticamente incoherente, dado que "el público" en este contexto es sólo otra forma de denominar a la comunidad como un todo. Y sería extraño decir que aunque la comunidad quisiera, por medio de sus legisladores, enmendar la Ley de la Libertad de Información para eximir de ella a los informes preliminares de las investigaciones médicas, porque la comunidad cree que la integridad de esa investigación es más importante que la información a 
la que renuncia debido a ese eximente, no debe hacerlo en virtud de su derecho a obtener esa información. El análisis de los asuntos relativos a la Primera Enmienda mejoraría mucho si el interés del público en la información, que podría ser contrarrestado por su interés en la mantención del secreto, no fuese mal etiquetado como un "derecho" a saber.

Quizás ahora queda más claro por qué creo que es una mala estrategia de la prensa intentar ampliar el ámbito de la Primera Enmienda. Siempre existe el riesgo de que las cortes - y la profesión legal en general- se decidan por una teoría respecto a una disposición constitucional específica. Si la protección de la Primera Enmienda se limita al principio de que nadie que quiera expresarse sobre temas o en maneras que estime importantes pueda ser censurado, entonces la única teoría de la Primera Enmienda será una teoría de los derechos individuales. Y esto significa que los preceptos de la libertad de expresión no pueden ser contrarrestados por el argumento de que en algunos casos particulares la censura y la regulación son más beneficiosas para el interés público.

Pero si la protección de la Enmienda se invoca cuando el alegato ha de fundarse en un argumento que busca proteger a la audiencia - por ejemplo, si se declara que la opinión editorial de los periodistas no debe ser objeto de demandas por injurias y difamación porque esto los haría menos efectivos en su búsqueda de noticias para lectura del público—, la única teoría que podría justificar un alcance tan amplio de la Enmienda tendrá que ser una teoría de política. No es sorprendente que en los casos de los que se queja la prensa, las posturas minoritarias - que sostienen que a la prensa se le debería haber dado lo que pedíacontengan muchos argumentos de política y pocos de principio. En el caso Herbert, por ejemplo, el juez Brennan fundamentó su postura disidente en una teoría de la Primera Enmienda muy similar a la teoría de Mill destinada a proteger a la audiencia. Brennan citó el famoso comentario de Zechariah Chafee: "La Primera Enmienda protege ... el interés social en la búsqueda de la verdad, de manera que el país pueda no sólo adoptar el curso de acción más sensato, sino también pueda llevarlo a cabo de la manera más sensata ...”.

Pero estas apelaciones al bienestar general del público se prestan para que se replique que, considerados todos los factores, el interés real del público se vería más favorecido en algunos casos por la censu- 
ra que por la publicación. En contraste, si la Enmienda se limita a su objetivo medular, cual es la protección del emisor, puede proporcionar, al apelar a los derechos individuales en lugar de apelar al bienestar general, un principio de derecho lo suficientemente fuerte para otorgar una protección importante en un caso que verdaderamente concierna a la Primera Enmienda, como el de The Progressive. Pero si la Enmienda pasa a ser muy amplia, sólo puede defenderse con argumentos de política como los que dio Brennan. Es decir, ella sólo puede defenderse con los argumentos que precisamente la hacen más vulnerable en los casos en que más se la necesita.

\section{III}

Si nos centramos exclusivamente en lo medular de la Primera Enmienda, que protege a quien emite una opinión por una cuestión de principios, el historial reciente de la Corte y del Congreso se ve mejor, aunque dista de ser impecable. Antes del caso Snepp, ese núcleo del principio de la libertad de expresión se vio amenazado, podría decirse, sólo en los casos que le importan muy poco a la prensa, como los de obscenidades, y en el The Progressive, que sólo se trató de una sentencia de una corte de distrito y que concluyó de todos modos en un triunfo para la prensa. Los otros fallos que tanto enfurecieron a los periodistas — como Farber y Herbert - fueron todos dictámenes que simplemente no acogieron los argumentos de política que planteaban los periodistas, a saber, que el público se vería en general más beneficiado si los corresponsales gozaran de privilegios especiales. Los escalofriantes efectos que tendrían estos fallos, según las predicciones de la prensa, no se han materializado; de hecho, Mike Wallace, uno de los reporteros que se negó a ser interrogado en el caso Herbert, hace poco expresó que tal vez la prensa habría merecido perder ese juicio.

En todo caso, si la democracia funciona con mediana eficacia, y si los argumentos de política de los periodistas son sensatos, a la larga van a obtener los poderes que buscan a través del proceso político, y por lo tanto no han perdido nada de sempiterna importancia con estos fallos judiciales que les han negado esos poderes. Porque si en verdad el público se ve más beneficiado en general cuando la prensa es poderosa, cabría esperar que el público se dé cuenta, tarde o temprano, de 
dónde recaen sus intereses — tal vez con la ayuda de la propia prensa. Salvo en casos como el de Farber, en que la ampliación del poder de la presa infringiría los derechos de los individuos —en ese caso el derecho a un juicio imparcial-, la sociedad puede entonces darle a la prensa lo que ésta quiere a través de la legislación.

Sin embargo, surge la pregunta de si el fallo del caso Richmond Newspapers (en el cual, como mencioné, la Corte Suprema sostuvo que en la ausencia de fuertes intereses contrapuestos los periodistas tienen derecho a presenciar los juicios criminales) muestra que la Corte ahora suscribe una teoría de la Primera Enmienda que va más allá del principio medular y que abarca la protección del bienestar general de la audiencia. Es cierto que el resultado de ese caso podría justificarse con un argumento de política como el que expuso Brennan en el caso Herbert. La opinión de Burger en el caso Richmond Newspapers señala, por ejemplo, que el interés del público en temas criminales se ve más satisfecho, e incluso también su inevitable deseo de que los culpables reciban su castigo, cuando la prensa sigue e informa sobre los juicios. Sin embargo, una lectura cuidadosa de las opiniones en este juicio muestra que aunque los siete jueces de la Corte Suprema que votaron a favor de la prensa (el juez Rehnquist se opuso y el juez Powell no participó en el caso) procedieron en base a teorías un tanto distintas, dos argumentos dominaron, ninguno de los cuales era estrictamente un argumento de política del tipo propuesto por Mill.

El primero, enfatizado especialmente por Burger, y al parecer por Blackmun, vincula la protección de la Primera Enmienda a la historia. Según este argumento, si algún proceso importante del gobierno ha estado abierto al público en virtud de antiguas costumbres de la jurisprudencia anglo-estadounidense, entonces los ciudadanos tienen un derecho, amparado por la Primera Enmienda, a la información sobre ese proceso, y por lo tanto la prensa tiene un derecho, por derivación, a conseguir y entregar esa información. El derecho de los ciudadanos no es absoluto, puesto que se debe ceder si, por ejemplo, entra en conflicto con los intereses del acusado. Pero el argumento sigue en pie en un caso, como en el de Richmond Newspapers, en el que no hay intereses importantes del acusado que estén en juego, o cuando la Corte puede proteger esos intereses con mecanismos distintos a la prohibición de la presencia de la prensa en los juicios. 
A mi juicio, este argumento basado en la historia es débil porque no hay razón para que la costumbre pase a ser un derecho, salvo que exista un argumento de principio independiente de por qué la gente tiene un derecho a aquello que recibe por costumbre. En todo caso, de ningún modo se trata de un argumento que requiera que las cortes decidan si el bienestar social se ve favorecido, considerados todos los factores, al negarle a la prensa acceso a información o a relatos escalofriantes sobre cualquier caso particular. Lo que sostiene es que la prensa debe ser admitida en los juicios criminales a menos que haya alguna razón especial en contra de ello, y no sólo el balance del bienestar general.

El segundo argumento, enfatizado especialmente por Brennan, es más importante y también más complejo. Éste insiste en que la prensa necesita de alguna protección especial, no sólo para promover el bien general sino también para preservar la estructura misma de la democracia. La frase clásica de Madison, para este argumento es citada con frecuencia en los alegatos de la prensa en juicios de derechos constitucionales. Según Madison, "un gobierno del pueblo, sin información pública o sin los medios para acceder a ella, no es sino el prólogo de una farsa o de una tragedia; o quizás de ambas ... un pueblo que pretende autogobernarse debe armarse con el poder que otorga el conocimiento".

Éste no es el argumento de Mill, quien planteó que mientras más información tenga la gente, mayor será la probabilidad de que las personas alcancen, en general, lo que más anhelan. Más bien se trata del argumento de que los individuos necesitan cierta información para incluso ser capaces de determinar lo que quieren, y para participar como iguales en el proceso de gobernarse a sí mismos. El argumento de política formulado por Mill es abierto: cuanta más información, mejor. Pero el argumento madisoniano de la estructura democrática no puede ser abierto, pues entonces terminaría siendo paradójico y autocontradictorio.

Lo anterior es así porque toda ampliación de la Primera Enmienda es, desde la perspectiva democrática, un arma de doble filo. Intensifica la democracia, ya que la información pública acrecienta el poder general de la sociedad. Pero también contrae a la democracia, puesto que cualquier derecho constitucional inhabilita a la asamblea legislativa que ha sido elegida por votación popular a legislar de un modo diferente aunque así lo 
quisiese, y entonces el poder general de la sociedad disminuye. La democracia supone que la mayoría tiene efectivamente poder para gobernar conforme a lo que estima es el interés general de la sociedad. Si es así, cualquiera extensión de la protección a la libertad de expresión y de la prensa tanto aumenta como reduce ese poder, en estas dos formas diferentes. Cualquier individuo en particular podría ser más efectivo políticamente porque sabrá más acerca de, por ejemplo, instalaciones de energía atómica. Pero también su efectividad política podría disminuir porque perderá el derecho a elegir a parlamentarios que votarían a favor de censurar la información sobre ese tema. Quizás estime, tras sopesar los pros y contras, que esto acarree en su conjunto una pérdida de poder político, en especial si él preferiría sacrificar el acceso a esa información y contar así con la ganancia en seguridad que resulta del hecho de que nadie cuente con esa información.

Toda decisión relativa a la censura confronta a los ciudadanos con este tipo de dilema de costo-beneficio, y no es posible decir que necesariamente se gana poder político cuando el tema se retira del ámbito de la política y lo decide, en cambio, la Corte Suprema. De hecho, sería tentador argumentar lo contrario: que una democracia genuina y vehemente no requeriría la Primera Enmienda, ya que entonces toda controversia específica de censura se decidiría por la voluntad mayoritaria del Congreso y de las legislaturas estatales. Pero eso es ir muy lejos, porque, como advirtió Madison, las personas necesitan una estructura general y protegida de información pública para decidir al menos en forma inteligente si se desea más o menos información. No hay democracia entre esclavos que pudieran hacerse del poder si tan sólo supiesen cómo hacerlo.

Sin embargo, el error opuesto es igualmente grave. Esto se debe a que es absurdo suponer que el electorado estadounidense, que ya tiene acceso a una cantidad mucho mayor de información pública, y más sofisticada, de la que muestra estar dispuesto a utilizar, ganaría en poder democrático si la Corte Suprema decidiera, por ejemplo, que el Congreso no puede enmendar la Ley de Libertad de Información para eximir los informes del Centro de Control de Enfermedades, sin importar cuantas personas piensen que ese eximente es una buena idea. Por ende, el argumento de la estructura democrática requiere, por su lógica interna, trazar la línea del umbral entre las interpretaciones de la Prime- 
ra Enmienda que protegerían la democracia y las que violentarían la democracia.

Hay una manera evidente, aunque difícil, de trazar esa línea de umbral. Requiere que la Corte Suprema describa, al menos en términos generales, qué forma de intromisión en los poderes de la prensa trabarían el flujo de información al público hasta privar a éste de los medios necesarios para que pueda decidir, en forma inteligente, si es más conveniente revertir esa restricción de la prensa mediante leyes complementarias. La Corte podría decidir, por ejemplo, que la negación por parte de un organismo de gobierno, en forma generalizada y arbitraria, a suministrar información o darle a la prensa la oportunidad de investigar, dejando así al público sin información para determinar si las prácticas de dicho organismo merecen mayor indagación, cae en el lado incorrecto del umbral ${ }^{7}$. Sin embargo, no resulta verosímil suponer que el público se vería tan dramáticamente invalidado si la prensa fuese excluida de los pocos juicios penales en que así lo solicitase la defensa del acusado, estuviese la fiscalía de acuerdo y el juez estimase que los intereses de justicia se verían mejor servidos si se procediera a esa exclusión. La ciudadanía de un estado que adoptara esta práctica mantendría su competencia para decidir si la desaprueba, y si así fuese, para abolirla a través del proceso político. Por lo tanto, si el argumento madisoniano de la estructura democrática se aplica a casos particulares mediante la idea de un umbral de competencia pública, el caso Richmond Newspapers debería haberse resuelto a la inversa.

Sin embargo, la opinión del juez Brennan en este caso muestra otro modo de emplear este argumento de la estructura. Él señaló que a pesar de que en principio la prensa debería gozar de acceso total a la información, en la práctica se requiere dibujar alguna línea mediante una evaluación de los hechos en juego en cada caso concreto, y no por medio de un umbral del tipo recién explicado. Esto es, él supondría que todo obstáculo que restrinja el acceso de la prensa a la información es inconstitucional, salvo que exista un conflicto real de intereses que justifique tal restricción, en cuyo caso el dilema sería determinar cuál de los intereses — el derecho de la ciudadanía a la información o los

${ }^{7}$ La Corte se enfrentó a ese tema en el caso Houhins $v$. KGBX, en el que los administradores de la prisión se rehusaron a darle a una estación de televisión oportunidad alguna para que investigara las condiciones del penal. Tal vez debido a que dos jueces no pudieron participar en el caso, la Corte no alcanzó una decisión concreta sobre el principio legal envuelto. 
otros intereses que están en juego - tiene mayor peso. En el caso Richmond Newspapers el juez Brennan no encontró ningún conflicto de intereses, y por ende consideró innecesario discutir la magnitud del daño que sufriría la estructura democrática debido a la exclusión en cuestión.

Todo esto acerca peligrosamente el argumento de Brennan a un argumento de política similar al de Mill. A pesar de que Brennan ha sido uno de los defensores más fervientes de la libertad de expresión, su argumento sugiere la censura en aquellos casos en que, una vez considerada toda la información, se estima que el bienestar general se vería más beneficiado con la censura o, mejor dicho, cuando la sociedad así lo crea. Por lo que el equilibrio descrito por Brennan podría inclinarse en contra y no a favor de The Progressive, por ejemplo. No es absurdo suponer que la publicación de conocimientos atómicos aumenta en algún grado el riesgo para la sociedad. Pero es absurdo suponer que impedir dicha publicación, considerada en sí misma como lo propone Brennan, podría menoscabar de alguna manera evidente la estructura democrática estadounidense, o dejar al público, que tiene considerables conocimientos generales sobre los peligros atómicos, incapacitado para decidir si cambiar o no de opinión y eliminar la restricción mediante la acción política ordinaria. Brennan mismo distinguiría entre los casos de acceso a la información, como el de Richmond Newspapers, y los casos de abierta censura, como el de The Progressive. Pero la teoría que expuso para tratar a los primeros casos fácilmente podría transformarse en una teoría estructural general de la Primera Enmienda, y entonces la libertad se vería afectada.

\section{IV}

Los procedimientos empleados por la Corte Suprema en el juicio de Snepp fueron extraordinarios e indefendibles. No obstante, considero que la decisión también fue errónea en los méritos y no simplemente en materia de procedimiento y reparación. Para efectos de precisar el conflicto constitucional en cuestión, supongamos los siguientes hechos, algunos de los cuales mencioné antes. Al ingresar a la CIA Snepp firmó un contrato que lo obligaba a entregar para revisión de la institución todo material que pudiera querer publicar después sobre la CIA. De no haber estado de acuerdo con las cláusulas del contrato, no le 
habrían dado el cargo. Decent Interval, el libro que publicó sin someterlo a revisión previa, no contenía información reservada. Si nunca hubiese trabajado para la CIA y no hubiese firmado ese contrato, habría podido publicar el mismo libro, con la misma información, sin tener que pasar por una aprobación previa, y no habría quedado sujeto a pena legal alguna. En efecto, si el Congreso aprobara una ley exigiendo que los autores que escriban libros sobre la CIA entreguen sus borradores para que la CIA los apruebe previamente, esa ley sería inconstitucional porque violaría los derechos que la Primera Enmienda les reconoce a los autores ${ }^{8}$.

De modo que la pregunta es ésta: cuando Snepp se unió a la CIA y firmó el acuerdo, ¿̇renunció a sus derechos constitucionales a publicar información no reservada sobre la CIA, un derecho que obviamente tiene cualquier persona que no está en la posición de él? He planteado la pregunta así para explicar que uno de los argumentos utilizados por la CIA contra Snepp no ha lugar. La CIA alegó que el requisito de someter a revisión que le había impuesto a Snepp en el contrato no le hacía daño alguno al autor. Si la revisión ponía en evidencia que el autor pretendía revelar información secreta, luego la CIA actuaría para evitar que eso sucediera. Pero, como correctamente alegó la CIA, Snepp no tiene derechos constitucionales para publicar información reservada. Snepp seguía siendo libre de publicar cualquier información no reservada una vez que hubiese finalizado la revisión, tal como era libre de hacerlo cualquiera otra persona. El requisito contractual de revisión de los materiales antes de su publicación (argumenta la CIA) sólo le da a la CIA la legítima oportunidad de evaluar por sí misma si lo que se pretende publicar es secreto, y tomar las medidas para detener su publicación si el material se considera reservado. Por ende, el contrato no constituía una renuncia a un derecho constitucional.

Pero si (como supongo) ni siquiera el Congreso podría obligar a quienes no trabajan para la CIA a entregar sus manuscritos para una revisión previa, entonces no puede la CIA argumentar que esta revisión no tiene nada que ver con la censura. La experiencia de Victor Mar-

\footnotetext{
${ }^{8}$ Se trata desde luego de una cuestión diferente (que no puedo considerar en esta ocasión), a saber, hasta dónde el Congreso puede llegar a prohibirles constitucionalmente a los ciudadanos en general, y a ex agentes en particular, que publiquen información que tal vez sea genuinamente secreta y peligrosa, por ejemplo los nombres de los agentes actuales, como se propone hacer el proyecto de ley que describí antes.
} 
chetti con la CIA después de entregar su manuscrito demuestra (si esa demostración fuese en verdad necesaria) cómo este requisito hace que lo escrito por el autor sea objeto de acuerdos, negociaciones y atrasos, todo bajo la inminente amenaza de llevarlo a juicio, en lugar de tratarse de un asunto respecto a lo que el autor realmente quiere decir, como la Primera Enmienda insiste en que debería ser ${ }^{9}$.

Por lo tanto, la pregunta es simplemente si Snepp renunció o no a derechos constitucionales que de lo contrario habría tenido. Nuevamente todo depende de la postura que uno adopte respecto al sentido y fuerza del derecho a la libertad de expresión. En la petición de una segunda audiencia a la Corte Suprema, los abogados de Snepp argumentaron que "las memorias no revisadas de ex funcionarios de gobierno que habían desempeñado cargos de confianza, con acceso a información sobre los aspectos muy delicados de la seguridad nacional, han hecho contribuciones invaluables para su comprensión y el debate público. La publicación de innumerables escritos de ese tipo sin que se haya evidenciado un daño al bienestar de la nación, desmiente la necesidad de que los funcionarios de la CIA deban quedar sujetos a restricciones previas”. Este argumento no es persuasivo si sugiere que permitir que Snepp renuncie a la Primera Enmienda sería incorrecto porque ello atentaría contra el bienestar general.

Es verdad que si se les permite a la CIA y a otros organismos de seguridad imponer a sus funcionarios, como condición del empleo, el requisito de que sometan a revisión sus escritos antes de publicarlos, entonces el público, en el transcurso del tiempo, indiscutiblemente quedará privado de cierta información que de lo contrario habría adquirido. Sin embargo, los argumentos de política de la CIA para rebatir este punto - a saber, que la eficiencia de las operaciones de recolección de información se vería comprometida si la institución no tuviera la oportunidad de revisar los documentos escritos por sus ex funcionarios antes de su publicación — no son nimios. No hay duda de que la CIA

${ }^{9}$ La CIA en un inicio hizo una lista de 339 secciones del libro que a su juicio revelaban información reservada. En esta lista se incluía un pasaje sobre Richard Helms, tomado de los informes del Consejo Nacional de Seguridad, en el que Marchetti informaba que "lo que de otro modo habría sido una actuación impecable [de Richard Helms], la estropeó al pronunciar mal Malgay, ex Madagascar, al referirse a la joven república”. Marchetti y Knopf llevaron el asunto a juicio, en el curso del cual la CIA admitió que 171 de esas secciones no eran material reservado. 
ha exagerado la importancia de la revisión previa. Dice, por ejemplo, que las agencias extranjeras habrían dejado de proporcionarle información a los Estados Unidos si Snepp hubiese ganado el juicio. Estas agencias no son tan estúpidas como para suponer que la fuente principal de las filtraciones de información son los libros escritos por ex agentes. No obstante, incluso si descontamos esta exageración, sigue siendo verosímil que la CIA sea más eficiente si tiene la oportunidad de evaluar y discutir los distintos párrafos y pasajes de antemano, y alertar a sus amigos, incluidas las agencias de inteligencia extranjeras, sobre lo que pronto se estará vendiendo en las librerías.

Pero eso significa que existe un genuino asunto de política, de costo-beneficio, que determinar: ¿aumenta o disminuye el bienestar general en el largo plazo si libros como el de Snepp son objeto de dilaciones u hostigamiento? La pregunta de si Snepp renunció o no a sus derechos es una pregunta nueva del derecho constitucional, que no está resuelta por ninguna sentencia anterior de la Corte Suprema, ni por ninguna arraigada política constitucional a favor de la libertad de expresión. Si suponemos que se ha de resolver por un cálculo de costobeneficio de qué es más beneficioso para la comunidad como un todo en el largo plazo, como podría sugerir el argumento de los abogados de Snepp, entonces el argumento de que debe ser resuelta por el sistema judicial a favor de Snepp, en vez dejarla en manos del Congreso y de la ciudadanía, no es muy fuerte.

Pero el argumento de los abogados de Snepp es mucho más persuasivo, y a mi juicio acertado, si lo que se propone es prestar atención a los derechos de los ciudadanos que desean escuchar lo que quiere decir Snepp, en lugar de prestar atención al bienestar general. Porque estos ciudadanos creen que estarán en mejor posición de influir en las decisiones políticas relativas a la CIA si saben más sobre el comportamiento de la agencia, y su derecho constitucional a escuchar no debería verse cercenado por la decisión personal de Snepp de renunciar a su derecho a entregarles a ellos esa información.

Debo ahora decir algo sobre este derecho constitucional a escuchar. En su conjunto, la Constitución define y ordena las condiciones bajo las cuales deben vivir los ciudadanos en una sociedad justa, $\mathrm{y}$ entre esas condiciones es crucial que todos los ciudadanos puedan votar y participar en política como iguales entre sí. La libertad de 
expresión es esencial para la igualdad en la participación, pero también lo es el derecho de todo ciudadano a que otros, cuyo acceso a la información pudiese ser mayor, no se vean impedidos de comunicársela. Esto, claramente, no es un tema de política: no se trata de proteger la voluntad de la mayoría o de asegurar el bienestar general en el largo plazo. Así como la mayoría transgrede el derecho del emisor cuando lo censura, aun cuando la comunidad se vería más beneficiada con esa censura, también viola el derecho de todo potencial receptor que estima que su participación política se vería favorecida, ya sea en su efectividad o en el significado que para él tiene, si pudiese escuchar al emisor.

El derecho a escuchar es en general parasitario del derecho a la libertad de expresión, que constituye la médula de la Primera Enmienda, y suele ser adecuadamente protegido por la aplicación irrestricta de ese derecho medular a la libertad de expresión. Porque el derecho a escuchar no es el derecho a saber lo que nadie quiere decir ${ }^{10}$. Pero el derecho a escuchar se vería seriamente vulnerado si todos los organismos del gobierno estuviesen en libertad de exigir como condición de contratación que los funcionarios renuncien a su derecho a revelar después información que no es reservada sin haberla verificado primero con el organismo.

La ley, por supuesto, permite que los ciudadanos y las firmas privadas puedan exigir promesas de reserva con el fin de evitar la divulgación de secretos empresariales, contenidos de diarios personales u otros similares. Sin embargo, el caso de Snepp es distinto. El derecho a escuchar es parte del derecho de participar en política en un pie de igualdad, y es evidente que la información sobre el comportamiento de la CIA en Vietnam es más relevante a la actividad política que la información sobre secretos empresariales o asuntos personales de los ciudadanos privados $^{11}$.

${ }^{10}$ Como cuestión legislativa, es necesario reconocer un derecho constitucional independiente con el fin de proteger a quienes quieren escuchar a alguien que no tiene un derecho constitucional a hablar. La Corte Suprema ha sostenido, por ejemplo, que la Primera Enmienda protege a los ciudadanos estadounidenses que desean recibir material político de autores extranjeros, los cuales, por supuesto, no están protegidos por la Constitución de los EE. UU.

${ }^{11}$ Desde luego que en casos particulares las diferencias de este tenor pudieran ser diferencias de grado solamente. Los secretos comerciales, por ejemplo, podrían tener importancia política. Pero si así fuese, entonces el argumento en contra de hacer valer las renuncias a derechos constitucionales en esos casos es, en consecuencia, más fuerte. 
De modo que el problema de hacer valer contratos en que se renuncia al derecho a expresarse, tomando en cuenta el derecho, protegido constitucionalmente, que los demás tienen a escuchar, es un derecho que, al igual que otros problemas legales, requiere que se tracen líneas. En el caso de Snepp había dos líneas que podía seguir la Corte Suprema. Pudo haber dicho que las instituciones del gobierno, a diferencia de las personas o entidades privadas, jamás pueden obligar a la renuncia de un derecho constitucional como requisito de contratación. Esta distinción se justificaría por el hecho de que la información de los organismos gubernamentales es presuntamente de gran relevancia para la participación en política, mientras que la información sobre entidades privadas, aunque también podría ser gravitante, presuntamente no lo es.

O la Corte pudo haber dicho que un organismo gubernamental nunca puede exigir esa renuncia como condición de contratación de funcionarios, salvo que esa condición haya sido expresamente impuesta por el Congreso en vez de haber sido impuesta por el propio organismo. La justificación de ese requisito más débil se basaría en que esta decisión —la decisión de si la publicación de documentos de ex funcionarios sin previa revisión es una amenaza lo suficientemente grave para la seguridad nacional como para justificar la suspensión del derecho a escuchar- es una decisión que debería ser tomada por la legislatura nacional y no por una agencia (CIA) cuyos propio interés en la mantención de reserva podría comprometer su juicio al respecto. También podría ponerse en duda que este segundo y más débil requisito sea suficiente para cumplir con los estándares de la Primera Enmienda. Pero no es necesario seguir analizando aquí esta cuestión, puesto que ambos requisitos, el más fuerte y el más débil, habrían abogado por un fallo a favor de Snepp.

Cabe preguntarse, sin embargo, si un argumento distinto, que no depende del derecho de los otros a escuchar, sino directamente del propio derecho de Snepp a expresarse, también hubiera justificado una resolución que se rehúsa a hacer valer la renuncia de un derecho por vía contractual. Parecería que dicho argumento, apoyado directamente en los propios derechos de Snepp, ha de fracasar, ya que Snepp tomó libre e informadamente la decisión de aceptar un trabajo que le acarreaba el costo de renunciar a un derecho. Si Snepp (quien, como lo dijo sucintamente el abogado de la CIA, sabía que no se estaba uniendo a los boy scouts) libremente pactó renunciar a sus derechos de la Prime- 
ra Enmienda al aceptar que revisaran sus manuscritos antes de ser publicados, ¿por qué los tribunales deberían liberarlo de ese pacto ahora, cuando le resulta inconveniente? ¿Por qué los tribunales deberían ahora impedir que otras personas hagan ese mismo pacto en el futuro, como ocurriría si se pronunciaran ahora a favor de Snepp?

Éste fue el argumento de la CIA, y prevaleció. Pero no es tan fuerte como parece, dado que se basa en una analogía errada entre un derecho constitucional y un trozo de propiedad. La Primera Enmienda no reparte derechos como quien distribuye sellos de canje cuya finalidad es aumentar la riqueza total de cada ciudadano. La Constitución en su conjunto establece, como ya mencioné, las condiciones bajo las cuales ha de considerarse que los ciudadanos forman una comunidad de iguales. Un ciudadano individual no tiene más capacidad para redefinir esas condiciones que la que tiene la mayoría. La Constitución no le permite venderse como esclavo ni regalar su derecho a elegir su religión. Y no porque nunca le convenga realizar semejante trato, sino porque no se puede tolerar que un ciudadano sea esclavo o que su libertad de conciencia se encuentre hipotecada.

La pregunta que debe hacerse, al considerar si algún derecho constitucional en particular puede ser cedido, es la siguiente: ¿la renuncia a ese derecho dejará a una persona en una condición que, según la Constitución, constituye una negación de la igualdad? Puesto que la definición de igualdad de posición que entrega la Primera Enmienda incluye el derecho a informar a nuestros conciudadanos aquello que creemos importante, así como el derecho a ser fieles a nuestra conciencia en asuntos religiosos, no debería haber mayor libertad para transar el derecho a la libertad de expresión que para transar el derecho a profesar una religión. Por esa razón la analogía con los derechos a la propiedad es tan deficiente. Si hago un trato financiero que después lamentaré, habré perdido dinero. Pero mi posición como alguien que participa en política como igual no se ha visto afectada, al menos según la definición constitucional de lo que es la esencia de esa posición. No me he vendido a la esclavitud ni a una situación que la Constitución considera como parte de la esclavitud.

Nuevamente, el argumento no justifica la conclusión de que una persona jamás debería tener la facultad de acordar no publicar cierta información o de obligarse a someterla a una revisión previa. Porque no todos esos acuerdos dejan al individuo en una posición que comprome- 
te su condición como igual político. Por consiguiente, la Corte Suprema debe trazar una línea para distinguir entre renuncias permisibles y no permisibles del derecho constitucional a expresarse, y cualquiera de las líneas que definimos al considerar, precisamente ahora, el derecho de la audiencia a escuchar, podría ser adecuada para proteger el derecho del emisor a la libertad de expresión.

Esto es, la Corte podría decir que los organismos gubernamentales no pueden exigir ningún tipo de renuncia de derechos como condición de contratación, o que ninguna renuncia de ese tipo es admisible salvo que haya sido específicamente autorizada por el Congreso. Pero la Corte, en su breve e insatisfactoria opinión per curiam, no consideró estas posibles distinciones, cualquiera de las cuales hubiese respaldado el alegato de Snepp. La Corte dio por sentado que todos los empleados de organismos gubernamentales podrían renunciar a sus derechos de la Primera Enmienda, incluso sin la autorización específica del Congreso. Esa presunción comete el error de suponer que un derecho constitucional es un simple trozo de propiedad personal.

Por ende se debería haber sostenido que Snepp no había renunciado a sus derechos de la Primera Enmienda. Ésta es la conclusión necesaria para proteger el derecho de los demás a escuchar, como también para proteger la independencia del mismo Snepp. Pero este argumento a favor de Snepp está ligado a la concepción que defendí anteriormente sobre la libertad de expresión y la Primera Enmienda. Depende del supuesto de que la libertad de expresión es un asunto de principio, y que por lo tanto hay gran injusticia, y no sólo una amenaza abstracta al bienestar general de la comunidad, cuando alguien que desea expresar lo que piensa es amordazado, revisado o dilatado. Sólo si la libertad de expresión se percibe bajo esa luz, queda claro por qué es importante proteger incluso a un ex funcionario de la CIA que firmó un contrato y sabía que no se estaba uniendo a un grupo de boy scouts. Los casos Farber y Herbert muestran por qué la Primera Enmienda, así concebida, no le otorgará a la prensa todos los poderes y privilegios que ésta quisiera tener. El caso Richmond Newspapers nos ilustra por qué podría incluso quitarle a la prensa algo de lo que había llegado a conseguir. Pero los casos The Progressive y Snepp revelan por qué esa concepción es, sin embargo, esencial para la democracia constitucional de los EE.UU. La Primera Enmienda debe ser protegida de sus enemigos, pero también debe ser resguardada de sus amigos más cercanos. 


\section{REFERENCIAS}

Dworkin, Ronald: Taking Rights Seriously. Harvard University Press, 1977.

- "The Rights of Myron Farber”. En The New York Review of Books, octubre 26, 1978.

Hentoff, Nat: The First Freedom: The Tumultuous History of Free Speech in America. Delacorte, 1979.

Marchetti, Victor y John D. Marks: The CIA and the Cult of Intelligence. Knoff, 1974.

Shawcross: Sideshow. Kissinger, Nixon and the Destruction of Cambodia. Simon and Schuster, 1979.

Snepp, Frank: Decent Interval. An Insider's Account of Saigon's Indecent End Told by the CIA's Chief Strategy Analyst in Vietnam. Random House, 1977.

Woodward, Bob y Scott Armstrong: The Brethren. 1979. 